\title{
IMPACT OF COVID-19 ON PREGNANCY AND ITS OUTCOIME IN ZONAL MILITARY HOSPITAL
}

KEY WORDS: COVID-19, RTPCR, APGAR, Vertical

Transmission

\section{Dr Binay Mitra Dr Dhananjay Borse* Dr I J Singh Dr Aparna Sharma}

HOD, Obstetrics and Gynecology Dept Military Hospital Jammu, India

Classified Specialist, Obstetrics and Gynecology Dept Military Hospital Jammu, India*Corresponding Author

Commandant Military HospitalJammu, India

Graded Specialist, Obstetrics and Gynecology Dept Military Hospital Jammu, India

\begin{abstract}
Introduction : The corona virus disease 2019 [COVID-19] has rapidly spread worldwide and is now a global pandemic. It is matter of concern whether the COVID-19 affects the pregnancy and its outcome. In this study, investigation was done to determine the possibility of effects of COVID-19 on pregnancy and its outcome. Materials and Methods : A total of 1014 pregnant women were included in the study, from lst April to $30 \mathrm{Nov} 2020$ at a zonal military hospital. There were 148 women who tested COVID-19 RT-PCR [reverse transcriptase polymerase chain reaction] positive and remaining 866 were COVID-19 negative. Findings of antenatal complications and perinatal outcome were compared in both the groups. Results : The incidence of COVID-19 positive pregnant women was found to be $14.59 \%$. No increase in rate of antenatal complications was seen in COVID-19 positive patients. Cesarean delivery rate was more in the COVID-19 positive group $(52 \%)$ as compared to COVID-19 negative group (38\%), ( $p>0.05)$. Low APGAR score (0-3) was observed in $1(0.67 \%)$ neonate of COVID-19 positive mothers and in $9(1.03 \%)$ neonates of COVID-19 negative mothers. Overall 148 neonates were tested for the possibility of vertical transmission, 145 neonates were negative in RT-PCR, while 3 were positive.Conclusion : There is no significant effect of COVID-19 infection on maternal and foetal outcome in pregnancy and possibility of vertical transmission of the COVID-19 infection can not be ruled out.
\end{abstract}

\section{Introduction :}

COVID-19 is now considered a pandemic since World Health Organization (WHO) announcement on March 11, 2020.The patients of COVID-19 can present with array of symptoms. Most common are fever, cough, fatigue or mayalgia, headache, loss of taste or smell with some cases developing into life threatening pneumonia. The mode of transmission is by way of droplets which can occur when the patient sneezes or coughs. The incubation period varies from 2 days to 2 weeks following exposure to the virus [1]. The diagnosis of COVID-19 infection done presently by detection of the viral RNA by RT-PCR (Reverse Transcriptase Polymerase Chain Reaction) from the nasopharyngeal mucosa.

Pregnant women need special attention in this situation as physiological modulation in the immune system during pregnancy puts them and their neonates at increased risk of negative outcomes of COVID-19 infection [2].

According to Center for Disease Control and Prevention (CDC), much is still unknown about the effects of COVID-19 on the pregnancy and neonatal outcome [3].

Therefore, it is important to gain knowledge about pregnancy and its perinatal outcomes during the COVID-19 pandemic, including the possibility of vertical transmission. In this study, an attempt is made to demonstrate the effects of COVID-19 on pregnancy and its perinatal outcome and the possibility of vertical transmission.

\section{Materials and Methods :}

This is a prospective observational study done in the Department of Obstetrics and Gynecology at Zonal Military Hospital. Approval of institutional ethics committee was obtained before starting the study. Informed consent was obtained from each patient prior to participation.

A total of 1014 patients were included in the study, who were in third trimester or labour, from lst April to 30 Nov 2020. 148 women tested COVID-19 positive and 866 women were COVID-19 negative. Aim of the study was to assess the maternal morbidity due to COVID-19 in the pregnant patients and to assess the effects of COVID-19 infection on perinatal outcome along with vertical transmission Detailed history of patients like age, parity, gestational age, mode of delivery/ outcome, neonatal APGAR score were noted. The testing of all the pregnant women for COVID-19 was done by COVID-19 RT-PCR.

Symptoms like fever and cough, oxygen saturation and laboratory findings like $\mathrm{CBC}, \mathrm{C}$ reactive protein were recorded in COVID-19 positive mothers. For neonates born to mother with COVID-19 infection, nasopharyngeal swab was collected within $24 \mathrm{hrs}$ of birth and sent for COVID-19 RT-PCR test and analysed.

\section{Results :}

Total of 1014 pregnant women were analyzed. Demographic parameters like age, parity, mode of delivery, neonatal APGAR, vertical transmission was taken into consideration.

Demographic profile [n-1014]

Table:1

\begin{tabular}{|c|c|c|}
\hline Parameters & Covid positive & Covid Negative \\
\hline Mean age & $28 \pm 7$ & $26 \pm 5$ \\
\hline Parity & $\begin{array}{c}\text { Primigravida-60 } \\
{[40.54 \%]} \\
\text { Multigravida- } 88 \\
{[59.46 \%]}\end{array}$ & $\begin{array}{c}\text { Primigravida-520 [61\%] } \\
\text { Multigravida- 346 } \\
{[39 \%]}\end{array}$ \\
\hline $\begin{array}{c}\text { Mode of } \\
\text { delivery }\end{array}$ & $\begin{array}{c}\text { Vaginal-72 [48\%] } \\
\text { Cesarean -76 } \\
{[52 \%]}\end{array}$ & $\begin{array}{c}\text { Vaginal -537 [62\%] } \\
\text { Cesarean -329 [38\%] }\end{array}$ \\
\hline Total & 148 & 866 \\
\hline
\end{tabular}

Symptoms like fever and cough were taken into consideration.Out of 148 COVID-19 positive patients 10 patients reported having fever, 5 patients reported having fever and dry cough, with oxygen saturation normal in all asymptomatic patients while one mother develop dyspnea with hypoxia after cesarean delivery and was on oxygen support for 8 days. 

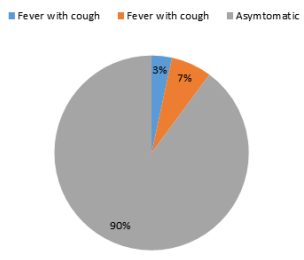

Antenatal complications like premature rupture of membranes [PROM], oligohydramnios, preterm labour, intrauterine growth restriction and intrauterine fetal demise [IUFD] was also compared in COVID-19 positive and COVID19 negative group. No increase in antenatal complications seen in COVID-19 positive patients.

\section{Antenatal Complications}

\section{Table:2}

\begin{tabular}{|c|c|c|c|}
\hline $\begin{array}{c}\text { Antenatal } \\
\text { Complications }\end{array}$ & $\begin{array}{c}\text { Covid-19 positive } \\
\mathrm{N}=148\end{array}$ & $\begin{array}{c}\text { Covid -19 } \\
\text { negative } \\
\mathrm{N}=866\end{array}$ & $\mathrm{p}$ value \\
\hline $\begin{array}{c}\text { Oligohydramni } \\
\text { os }\end{array}$ & $2[1.35 \%]$ & $22[2.54]$ & $<0.05$ \\
\hline Preterm labour & $2[1.35 \%]$ & $49[5.65 \%]$ & $<0.05$ \\
\hline PROM & $3[2.02 \%]$ & $53[6.12 \%]$ & $<0.05$ \\
\hline IUGR & $1[0.67 \%]$ & $20[2.30]$ & $<0.05$ \\
\hline IUFD & 0 & $6[0.69 \%]$ & $<0.05$ \\
\hline
\end{tabular}

Neonatal outcome in respect to APGAR score was also compared in COVID- 19 positive patients and COVID-19 negative patients. No significant change in neonatal outcome was noted.

\section{Neonatal outcome $n=1014$}

Table:3

\begin{tabular}{|c|c|c|c|}
\hline Apgar score & Covid-19 positive & $\begin{array}{c}\text { Covid-19 } \\
\text { negative }\end{array}$ & p value \\
\hline $7-10$ & 145 & 834 & $<0.05$ \\
\hline $4-6$ & 2 & 23 & $<0.05$ \\
\hline $0-3$ & 1 & 9 & $<0.05$ \\
\hline
\end{tabular}

To determine the possibility of vertical transmission, neonates of COVID-19 positive patients were tested by COVID-19 RT-PCR. Out of 148 neonates, 145 neonates were negative in RT-PCR, while 3 were positive. All neonates were asymptomatic.

\section{RT PCR Test Result for Neonates $n=148$}

Table:4

\begin{tabular}{|c|c|}
\hline Parameters & Value \\
\hline RT-PCR positive & $3[2.02 \%]$ \\
\hline T-PCR Negative & $145[97.97 \%]$ \\
\hline Total & 148 \\
\hline
\end{tabular}

\section{Discussion :}

There is a very limited data currently available on maternal and fetal outcomes in COVID-19 infection in pregnancy. Chen et al. [4] reported the maternal-neonatal outcomes and vertical transmission potential of COVID-19 pneumonia in pregnant women. Their study focused on pregnant women who only delivered babies by LSCS, and no case has been reported for normal vaginal delivery.

Lam et al; [5] studied the clinical course and outcome of pregnancy in patients with infections caused by pathogens similar to COVID-19 pathogens. The study showed that complications including sepsis, acute kidney injury, and disseminated intravascular coagulation (DIC) were considerably increased in pregnant women. Besides, they observed that the use of mechanical ventilation and mortality were more common among them than others.

Several studies have reported that most women who were
COVID-19 underwent LSCS because of obstetric indications. $[4,6,7$,$] For vertical transmission in COVID-19 the data is$ limited. In one case series, three neonates were born vaginally (one singleton, one set of twins) and throat swabs for PCR at day one of birth were negative for COVID-19 in all three cases [8].

In study by Chen et al. (4) the amniotic fluid, cord blood, neonatal throat swab, from newborn neonates of COVID-19 positive mothers were negative for COVID-19. Mimouni F et al and Muhidin S et al have revealed about the possibility of the vertical transmission in pregnancy $[9,10,11]$

In our study results revealed that the most common symptoms among COVID- 19 positive pregnant women were fever, and cough. The majority of COVID-19 positive patients delivered by cesarean delivery and they were discharged from hospital with no significant complications. Antenatal complications were not increased in COVID-19 group. Besides this our analysis revealed that neonates with positive COVID-19 infection were diagnosed by nasopharyngeal swab test. All COVID-19 RTPCR positive neonates were asymptomatic.

\section{Conclusion:}

There is a very limited data currently available on maternal and fetal outcomes in COVID-19 infection in pregnancy.

In our study, the clinical outcome was satisfactory for both mothers and neonates and there were no maternal or neonatal deaths due to COVID-19 as compared to COVID-19 negative mothers and neonates. The results of the study suggested that there is no effect of COVID-19 infection on maternal and perinatal outcome in pregnancy.

In our study, three neonates out of 148 , tested positive for COVID-19 infection.

Though statistically not significant as shown by the $p$ value, the rare possibility of vertical transmission in pregnant women with COVID-19 infection cannot be completely ruled out. Finally, to determine whether if vertical transmission indeed occurs, further lager scale studies are needed to performed.

\section{References}

[1] CDC. 2019 Novel Coronavirus, Wuhan, China: Symptoms. CDC. Available at https://www.cdc.gov/coronavirus/2019-ncov/about/ symptoms.html. $26 \mathrm{Jan}$ 2020.

[2] Chen YH, Keller J, Wang IT, Lin CC, Lin HC. Pneumonia and pregnancy outcomes: a nationwide population-based study. Am J Obstet Gynecol. 2012;207 (4):288.-el-7. [PMC free article] [PubMed] [Google Scholar]

[3] Centers for disease control and prevention Corona-virus disease 2019 (COVID-19) [Internet]. Geneva:Centers for disease control and prevention; If you are pregnant, breastfeeding, or caring for young children. 2020, June 09 [cited 2020 Jun 10]; [about 10 screens]. Available from: https://www.cdc.gov/ coronavirus/2019-ncov/need- extraprecautions/ pregnancy-breastfeeding. html. [Google Scholar]

[4] Chen H, Guo J, Wang C, et al. Clinical characteristics and intrauterine vertical transmission potential of COVID-19 infection in nine pregnant women: a retrospective review of medical records. Lancet. 2020;395(10226):809-15.

[5] Thomas M, Koutsothanasis GA, Bomar PA. Upper respiratory tract infection. [Updated 2020 May 5]. In: StatPearls [Internet].Treasure Islad (FL): StatPearls Publishing; 2020 Jan, Available from: http://www.ncbi.nlm.nih.gov/ books/NBK532961/.

[6] Yu N, LiW, Kang Q, et al. Clinical features and obstetric and neonatal outcomes of pregnant patients with COVID-19 in Wuhan, China: a retrospective, singlecentre,descriptive study. Lancet Infect Dis. 2020;20(5):559-64.

[7] WHO. Corona virus disease 2019 (COVID-19). Situation report-72 https://www.who.int/docs/default-source/coronaviru se/situationreports/20200401-sitrep-72-covid-19.pdf?sfvrs n=3dd897l lb_2.

[8] Zhu H,Wang L, Fang $\mathrm{C}$ et al. Clinical analysis of 10 neonates born to mothers with 2019-nCoV pneumonia. Transl Pediatr. 2020:9:51-60.

[9] Mimouni F, Lakshminrusimha S, Pearlman SA, Raju T, Gallagher PG, Mendlovic J. Perinatal aspects on the covid-19 pandemic: a practical resource for perinatal-neonatal specialists. J Perinatol. 2020;40(5):820-6. [PMC free article] [PubMed] [Google Scholar]

[10] Muhidin S, Moghadam ZB, Vizheh M. Analysis of maternal coronavirus infections and neonates born to mothers with 2019-nCoV; a systematic review. Arch Acad Emerg Med. 2020;8(1):e49. [PMC free article] [PubMed] [Google Scholar]

[11] Parazzini F, Bortolus R, Mauri PA, Favilli A, Gerli S, Ferrazzi E. Delivery in pregnant women infected with SARS-CoV-2: a fast review. Int J Gynecol Obstet.2020; 150(1):41-6. [PubMed] [Google Scholar] 